\title{
Suboccipital craniectomy with or without duraplasty \\ What is the best choice in patients with Chiari type 1 malformation?
}

\author{
Flávio Ramalho Romero', Clemente Augusto de Brito Pereira²
}

\begin{abstract}
The best surgical treatment for Chiari malformation is unclear, especially in patients with syringomyelia. We reviewed the records of 16 patients who underwent suboccipital craniectomy at our institution between 2005 and 2008. Of the six patients who did not undergo duraplasty, four showed improvement postoperatively. Two patients without syringomyelia showed improvement postoperatively. Of the four patients with syringomyelia, three showed improvement, including two with a decrease in the cavity size. One patient showed improvement in symptoms but the syringomyelia was unchanged. The cavity size increased in the one patient who did not show improvement. Among the 10 patients who underwent duraplasty, improvements were noted in four of the five patients without syringomyelia and in all of the five with syringomyelia. There is a suggestion that patients with syringomyelia may have a higher likelihood of improvement after undergoing duraplasty. Key words: Chiari type 1, syringomyelia, suboccipital craniectomy, duraplasty.
\end{abstract}

Craniectomia suboccipital com ou sem duroplastia: qual a melhor escolha em pacientes com malformação de Chiari tipo 1?

\section{RESUMO}

A melhor opção de tratamento cirúrgico na malformação de Chiari é desconhecido, especialmente em paciente com siringomielia. Nós revisamos casos de 16 pacientes submetidos à craniectomia suboccipital em nossa instituição de 2005 à 2008. Dos 6 pacientes que não foram submetidos à duroplastia, quatro tiveram melhora pós operatória. Dois pacientes sem siringomielia tiveram melhora pós operatória. Dos quatro pacientes com siringomielia, três tiveram melhora, incluindo dois com diminuição do tamanho da cavidade. Um paciente teve melhora da sintomatologia mas a siringomielia não se modificou. Dez pacientes foram submetidos à duroplastia. Melhora foi observada em 4 de 5 pacientes sem siringomielia e 5 de 5 casos com siringomielia. Há uma sugestão de que pacientes com siringomielia possam ter uma maior taxa de melhora após serem submetidos à duroplastia.

Palavras-chave: Chiari tipo 1, siringomielia, craniectomia suboccipital, duroplastia.

\section{Correspondence}

Flávio Ramalho Romero

Rua Pascoal Vita 366 / 94

05445-000 São Paulo SP - Brazil

E-mail: frromero@ig.com.br

romeroncr@gmail.com

Received 26 October 2009

Received in final form 20 January 2010

Accepted 2 February 2010
Chiari malformation type I (CM1) consists of protrusion of the cerebellar tonsils through the foramen magnum, defined radiologically as tonsillar descent of $5 \mathrm{~mm}$ or more ${ }^{1-5}$. Although many individuals with CM1 are asymptomatic, the malformation can cause headaches, ocu- lar disturbances, otoneurological disturbances, lower cranial nerve signs, cerebellar ataxia or spasticity ${ }^{6,7}$. The onset of symptoms is usually in the third decade of life. Since many cases of CM1 are asymptomatic, prevalence estimates may not be accurate. However, a retrospective inves- 
tigation of brain magnetic resonance images (MRIs) reported that the prevalence of CM1 was one case in 1,280 individuals ${ }^{8}$.

CM1 has been associated with syringomyelia in 30 to $70 \%$ of patients ${ }^{4,5}$. The best surgical treatment for Chiari malformation is unclear, especially in patients with syringomyelia ${ }^{1-5}$. The various surgical approaches attempted have included suboccipital craniectomy, syringostomy, obex plugging, syringosubarachnoid shunting, ventriculoperitoneal shunting and fourth ventriculosubarachnoid shunting ${ }^{1-3,7,9-12}$. Posterior craniocervical decompression is the procedure currently most used for treating CM1 (alone or in association with syringomyelia, in the absence of hydrocephalus).

Patients with syringomyelia have a poorer outcome with surgery, compared with those without syringomyelia ${ }^{3,6,13-15}$. Craniocervical junction decompression in hindbrain-related syringomyelia achieves an improvement in symptoms in approximately two-thirds of patients $^{14}$. In a review of patients who underwent Chiari decompression with or without duraplasty, Matsumoto and Symon ${ }^{15}$ noted no difference in the reduction of syringomyelia and Munshi et al. ${ }^{15}$ showed that regarding the improvement in symptoms, patients without duraplasty had a significantly worse outcome, compared with those who underwent duraplasty.

In the present report, we review our experience with the treatment of CM1 in patients who underwent decompression with or without duraplasty.

\section{METHOD}

We reviewed the records of 16 patients who underwent Chiari decompressions at our institution between 2005 and 2008 (Table 1). Their histories were obtained from clinical charts, and the symptoms and their duration were determined. Preoperative magnetic resonance imaging scans were examined for the presence of syringomyelia. The diagnosis of Chiari malformation and syringomyelia was made exclusively by means of MRI in this series. The diameter of the syringomyelic cavity was measured in relation to the diameter of the spinal cord, as proposed by Fujii et al. ${ }^{11}$. The indications for surgery included but were not limited to progressive or disabling symptoms, such as headache or tussive headache; drop attacks; neck, arm, or back pain; swallowing difficulties; upperextremity numbness or tingling; or progressive scoliosis.

Postoperative clinical improvement was assessed from clinical notes and generally reflected subjective reports of improvement in symptoms, return to work and decreases in pain medication in relation to preoperative dosages. Radiological improvement was defined as any demonstrable decrease in maximum syrinx diameter, as seen on postoperative MRI scans.
Table 1. Clinical and radiological summary of the patients.

\begin{tabular}{ccccc}
\hline Patient & Age (yrs) & Sex & Syringomyelia & Duraplasty \\
\hline 1 & 34 & M & No & Yes \\
2 & 28 & F & Yes & Yes \\
3 & 23 & F & Yes & Yes \\
4 & 62 & F & Yes & No \\
5 & 42 & M & No & No \\
6 & 53 & F & No & Yes \\
7 & 29 & F & Yes & Yes \\
8 & 27 & M & Yes & No \\
9 & 55 & M & Yes & Yes \\
10 & 60 & F & No & Yes \\
11 & 36 & F & No & No \\
12 & 39 & F & Yes & Yes \\
13 & 52 & M & No & Yes \\
14 & 47 & F & Yes & No \\
15 & 29 & M & Yes & No \\
16 & 34 & F & No & Yes \\
\hline
\end{tabular}

M: male, F: female.

The specific surgical procedure, i.e. non-duraplasty (without durotomy) or duraplasty, was chosen by each surgeon on the basis of training and personal preference. All patients underwent decompressive suboccipital craniectomy extending at least $2 \mathrm{~cm}$ above the foramen magnum, with bilateral removal of the $\mathrm{C} 1$ laminae. Six of the patients then underwent removal of all dural scarring or bands on the outside of the dura, as described by Isu et al. ${ }^{16}$. Ten patients underwent bone removal and dural grafting using the fascia lata.

Follow-up was performed postoperatively at one, three and six months. Postoperative improvement or worsening of symptoms was determined and noted in the chart. For patients with postoperative MRI scans, the change in the size of the syrinx cavity was classified as improved (decreased maximum diameter), unchanged or increased. This study was approved by the local ethics committee.

\section{RESULTS}

The patient population ranged in age from 23 to 62 years (mean 40.625) and included six men and ten women. The follow-up period ranged from nine months to two years (Table 1).

Of the six patients who did not undergo duraplasty, four showed improvement postoperatively. Two patients without syringomyelia showed improvement postoperatively. Of the four patients with syringomyelia, three showed improvement, including two with a decrease in the cavity size. One patient showed improvement in 
Table 2. Clinical summary of patients who did not undergo duraplasty.

\begin{tabular}{cccc}
\hline Patient & Syringomyelia & $\begin{array}{c}\text { Syringomyelia } \\
\text { decrease }\end{array}$ & $\begin{array}{c}\text { Symptom } \\
\text { improvement }\end{array}$ \\
\hline 4 & Yes & Yes & Yes \\
5 & No & - & Yes \\
8 & Yes & No & No \\
11 & No & - & Yes \\
14 & Yes & Yes & Yes \\
16 & Yes & No & Yes \\
\hline
\end{tabular}

Table 3. Clinical summary of patients who underwent duraplasty.

\begin{tabular}{cccc}
\hline Patient & Syringomyelia & $\begin{array}{c}\text { Syringomyelia } \\
\text { decrease }\end{array}$ & $\begin{array}{c}\text { Symptom } \\
\text { improvement }\end{array}$ \\
\hline 1 & No & - & Yes \\
2 & Yes & Yes & Yes \\
3 & Yes & Yes & Yes \\
6 & No & - & No \\
7 & Yes & Yes & Yes \\
9 & Yes & Yes & Yes \\
10 & No & - & Yes \\
12 & Yes & Yes & Yes \\
13 & No & - & Yes \\
16 & No & - & Yes \\
\hline
\end{tabular}

symptoms but the syringomyelia was unchanged. The cavity size increased in the one patient who did not show improvement (Table 2).

Among the 10 patients who underwent duraplasty, improvement was noted in four of the five patients without syringomyelia and in all of the five with syringomyelia. All of the patients with syringomyelia underwent postoperative MRI; all showed a decrease in the volume of their syringomyelia and clinical improvement (Table 3).

When the dura was opened, the surgical complications included two cases of cerebrospinal fluid (CSF) leaks associated with aseptic meningitis in one patient; one case of subgaleal CSF or seroma collection that subsequently resolved with conservative treatment only; one case of superficial wound infections; and postoperative occipital nerve pain in one patient. When the dura was not opened, the only complication was a superficial wound infection that resolved.

\section{DISCUSSION}

Chiari type 1 malformations occur in the region where the brain and the spinal cord join ${ }^{1,4,15-17}$. In this disorder, the portions of the brain called the cerebellum and/or brainstem lie lower than usual. Often, a portion of the cerebellum called the cerebellar tonsils protrudes out of the base of the skull into the spinal canal. This protrusion causes pressure in the brain, thus contributing towards the symptoms that such individuals experience. The cause of CM1 is not known. Some CM1 cases are believed to be present at birth ${ }^{16}$.

The posterior fossa is smaller and shallower in patients with Chiari malformation, compared with that in normal individuals ${ }^{17}$. The cisterna magna is also small or absent in patients with $\mathrm{CM} 1^{18-20}$. Therefore, enlargement of the foramen magnum or creation of a cisterna magna is one goal of surgery ${ }^{20-23}$. Furthermore, cardiac-gated dynamic MRI scans have demonstrated obstruction of CSF flow at the craniocervical junction in these patients ${ }^{22-24}$. The postoperative flow velocity of CSF is improved in the majority of these patients ${ }^{25-30}$. This flow change may underlie the change in syringomyelia size observed postoperatively.

Several mechanisms for the pathogenesis of syringomyelia have been proposed. According to the theory of Gardner and Angel ${ }^{25}$, the obstruction of CSF flow at the craniocervical junction causes CSF to enter the cervical central canal. However, no such communication exists in the majority of these patients ${ }^{18,24}$ and therefore this theory cannot explain the formation of the cavity. Oldfield et al. ${ }^{18}$ proposed that CSF enters the spinal cord directly via the perivascular spaces, or so-called Virchow-Robin spaces, by means of arterial pulsations. This is consistent with studies that show movement of water-soluble contrast media from the subarachnoid space to the cavity. Aboulker ${ }^{1}$ considered that an increase in venous pressure in the epidural veins was the reason for the increase in fluid in the spinal cord, with subsequent hydromyelia. Recently, Stoodley et al. ${ }^{23}$ showed that, under normal conditions in a sheep model, CSF flows rapidly from the subarachnoid space to the perivascular spaces, and that this flow is dependent on arterial pulsations. With any obstruction to the flow of CSF in the central canal, such as at the craniocervical junction, a cavity can form that could subsequently enlarge.

Although the exact mechanism for the formation of the hydromyelia in Chiari malformation is still controversial, there is general agreement on the importance of decompressing the craniocervical junction in treatments for Chiari malformation and hydromyelia. Suboccipital decompression, with or without duraplasty, serves to directly relieve the bony compression at the craniocervical junction. However, most authors differ on the usefulness and safety of additional procedures, such as duraplasty, syringosubarachnoid shunting or obex plugging.

If the purpose of surgery for CM1 is enlargement of the cisterna magna ${ }^{19}$, thereby allowing improved CSF flow, adequate bone removal must be obtained in all patients. 
Three of our four patients with syringomyelia showed improvement with bone removal only, and two $(50 \%)$ of the four showed a decrease in the size of the syringomyelia. The two patients with a decrease in cavity size showed an increase in CSF space behind the cerebellum. The patient with no change in the cavity size showed no change in the CSF space behind the cerebellum. It is also possible that this patient harbored or developed arachnoid scarring or subarachnoid adhesions.

All of the five patients with syringomyelia who underwent duraplasty showed improvement and all five (100\%) showed a decrease in the size of the cavity. Four of the five patients without syringomyelia who underwent duraplasty showed clinical improvement. Four of our six patients showed a decrease in syringomyelia, with an improvement in symptoms, through bone removal alone. This improvement was associated with an increase in the size of the cisterna magna, presumably allowing improved CSF flow, thereby leading to resolution of the syringomyelia. It therefore seems that duraplasty provides a better chance of enlarging the size of the cisterna magna.

Complications such as electrolyte imbalances, transient postoperative swallowing problems and cerebellar infarctions have been reported after Chiari decompression ${ }^{1,3,17,21}$. CSF leaks occurred in two of our patients. The wounds were resutured, thus resolving the leaks. The subgaleal fluid collections that developed after surgery were also resolved, by means of tapping. Occipital nerve pain, as seen in one patient, is a well-known complication following posterior fossa surgery ${ }^{20}$. These minor complications would not ordinarily warrant concern. However, the fact that they occurred predominantly in the patients undergoing duraplasty is of some significance.

It is difficult to draw conclusions from a series of limited size; however, there is a suggestion that patients with syringomyelia may have a higher likelihood of improvement after undergoing duraplasty. Nevertheless, some patients showed a decrease in syringomyelia, with an improvement in symptoms, through bone removal alone. This improvement was associated with an increase in the size of the cisterna magna, presumably allowing improved CSF flow and thereby leading to resolution of the syringomyelia. It therefore seems that duraplasty provides a better chance of enlarging the size of the cisterna magna.

Performing duraplasty to treat Chiari I malformation may lead to a greater decrease in concurrent syringomyelia. However, a subset of patients whose syringomyelia will decrease through bone removal alone still exists. Further studies are needed in order to better characterize these patients and to determine which patients with Chiari I malformation are better served with bone decompression alone, and which patients will require duraplasty to resolve their syringomyelia.

\section{REFERENCES}

1. Dauser RC, DiPietro MA, Venus JL. Symptomatic Chiari I malformation in childhood: a report of 7 cases. Pediatr Neurosci 1988;14:184-190.

2. Duddy MJ, Williams B. Hindbrain migration after decompression for hindbrain hernia: a quantitative assessment using MRI. Br J Neurosurg 1991;5:141-152.

3. Gonçalves da Silva JA, Leiros da Costa MD, Holanda MMA, et al. Impacted cisterna magna without syringomyelia associated with spastic paraparesis: case report. Arq Neuropsiquiatr 2006;64:672-675.

4. Isu T, Iwasaki Y, Akino M, Abe H. Hydrosyringomyelia associated with a Chiari I malformation in children and adolescents. Neurosurgery 1990;26:591-596.

5. Quencer RM, Post MJD, Hinks RS. Cine MRI in the evaluation of normal and abnormal CSF flow: intracranial and intraspinal studies. Neuroradiology 1990; 32:371-391.

6. Aboulker J. Syringomyelia and intra-rachidian fluids. Parts I-XIII. Neurochirurgie 1979;25:1-144.

7. Armonda RA, Citrin CM, Foley KT, Ellenbogen RG. Quantitative cine-mode magnetic resonance imaging of Chiari I malformation: an analysis of cerebrospinal fluid dynamics. Neurosurgery 1994;35:214-224

8. Stover LJ, Bergan U, Nilsen G, Sjaastad O. Posterior cranial fossa dimensions in the Chiari I malformation: relation to pathogenesis and clinical presentation. Neuroradiology 1993;35:113-118.

9. Batzdorf U. Chiari I malformation with syringomyelia: evaluation of surgical therapy by magnetic resonance imaging. J Neurosurg 1988;68:726-730.

10. Blagodatsky MD, Larionov SN. Surgical treatment of "hindbrain related" syringomyelia: long-term results. Acta Neurochir (Wien) 1993;123:209-210.

11. Nohria V, Oakes WJ. Chiari I malformation: a review of 43 patients. Pediatr Neurosurg 1990;16:222-227.

12. Fujii K, Natori Y, Nakagaki H, Fukui M. Management of syringomyelia associated with Chiari malformation: comparative study of syrinx size and symptoms by magnetic resonance imaging. Surg Neurol 1991;38:161-162.

13. Barbaro NM, Wilson CB, Gutin PH, Edwards MS. Surgical treatment of syringomyelia: favorable results with syringo-peritoneal shunting. J Neurosurg 1984;61:531-538.

14. Matsumoto T, Symon L. Surgical management of syringomyelia: current results. Surg Neurol 1989:32:253-256.

15. Wan MJ, Hiroshi N, Tator, CH. Conversion to symptomatic Chiari I malformation after minor head or neck trauma. Neurosurgery 2008:63:748-753.

16. Cahan LD, Bentson JR. Considerations in the diagnosis and treatment of syringomyelia and the Chiari malformation. J Neurosurg 1982;57:24-31.

17. Nagib MG. An approach to symptomatic children (age 4-14 years) with Chiari type 1 malformation. Pediatr Neurosurg 1994;21:31-35.

18. Oldfield EH, Muraszk K, Shawker TH. Pathophysiology of syringomyelia associated with Chiari I malformation of the cerebellar tonsils: implications for diagnosis and treatment. J Neurosurg 1994;80:3-15.

19. McGirt MJ, Nimjee SM, Floyd J, Bulsara KR, George TM. Correlation of cerebrospinal fluid flow dynamics and headache in Chiari I malformation. Neurosurgery 2005;56:716-721.

20. Menezes AH. Chiari I malformations and hydromyelia: complications. Pediatr Neurosurg 1991;17:146-154.

21. Newman PK, Tereny TR, Foster JB. Some observations on the pathogenesis of syringomyelia. J Neurol Neurosurg Psychiatry 1981;44:964-969.

22. Taricco MA, Melo LRS. Retrospective study of patients with Chiari: malformation submitted to surgical treatment. Arq Neuropsiquiatr 2008;66:184-188.

23. Samii M, Klekamp A, Sepehrnia A, et al. Syringomyelia associated with Arnold Chiari malformation. Acta Neurochir (Wien) 1993;123:195.

24. Munshi I, Frim D, Stine-Reyes R, Weir BK, Hekmatpanah J, Brown F. Effects of posterior fossa decompression with and without duraplasty on Chiari malformation-associated hydromyelia. Neurosurgery 2000;46:1384-1390.

25. Gonçalves da Silva JA, Holanda MMA, Leiros da Costa MD, et al. Basilar impression associated with impacted cisterna magna, spastic paraparesis and distress of balance: case report. Arq Neuropsiquiatr 2006;64:668-671.

26. Dyste GN, Menezes AH. Presentation and management of pediatric Chiar malformation without myelodysplasia. Neurosurgery 1988;23:589-597.

27. Gardner WJ, Angel J. The cause of syringomyelia and its surgical treatment. Cleve Clin Q 1958;25:4-8

28. Imae S. Clinical evaluation on etiology and surgical outcome in syringomyelia associated with Chiari type I malformation. No To Shinkei 1997;49: 1131-1138.

29. Isu T, Sasaki H, Takamura H, Kobayashi N. Foramen magnum decompression with removal of the outer layer of the dura as treatment for syringomyelia occurring with Chiari I malformation. Neurosurgery 1993;33:844-849.

30. Thorn K, Quigley K, Huang MC, Myseros JS, Yaun A, Keating RF. Chiari 1.5 malformation: is it real? Neurosurgery 2008;62:1415 